\title{
Diseño de entornos educativos basados en aplicaciones interactivas de realidad aumentada y videojuegos para el aprendizaje activo de la Arqueología
}

\author{
Design of educational environments rased on interactive \\ applications using augmented reality and video games \\ for the active learning of archeology
}

Recibido: agosto 11 de 2016 | Revisado: setiembre 10 de 2016 | Aceptado: octubre 15 de 2016

\author{
NORMa LeÓN LESCANO ${ }^{1}$ \\ SANDRA EYZAGUiRRE MAMANI ${ }^{2}$ \\ James Gómez Illatopa ${ }^{3}$
}

1 Jefa del Laboratorio de Investigación Aplicada Universidad San Martín de Porres Perú nleonl@usmp.pe

2 Game Designer de videpjuegos y realidad aumentada. Universidad de San Martín de Porres - Perú sandra_eyzaguirre@usmp.pe

3 Técnico de Laboratorio. Universidad de San Martín de Porres - Perú james_gomez@usmp.pe

\begin{abstract}
Resumen
Esta investigación describe el diseño de un entorno educativo virtual mediante videojuegos de realidad aumentada denominado Cultiaventura. El entorno se ha desarrollado como prototipo de apoyo al aprendizaje activo de la Arqueología en Educación Primaria. La metodología empleada se basa en la unión del modelo educativo, fundamentado en competencias y el modelo de desarrollo incremental de software. Los resultados indican que el diseño ejecutado ha permitido crear recursos digitales interactivos, alineados a las rutas de aprendizaje del Ministerio de Educación del Perú.
\end{abstract}

Palabras clave: competencias, entorno educativo, diseño, realidad aumentada, videojuegos, Educación Primaria

\section{Abstract}

This paper describes the design of a virtual learning environment through an augmented reality videogame called Cultiventura. The environment has been developed as a prototype to support the active learning of archeology in elemental education. The methodology is based on the union of educational model based in competences and an incremental model of software development. The results indicate that the created design enabled the creation of interactive digital resources aligned to the learning paths of the Peruvian education ministry.

Keywords: competency, elemental educational, environment, design, augmented reality, video games, primary education 


\section{Introducción}

Este trabajo se ha desarrollado en el contexto del proyecto "Prototipo educativo de enseñanza gradual usando tecnología de realidad aumentada, con alta capacidad de interacción e integración web, para el aprendizaje constructivo de la Historia y Arqueología del Perú por los niños de Educación Primaria”, gracias al financiamiento del Programa Nacional de Innovación para la Competitividad y Productividad - Innóvate Perú (Innóvate Perú, 2016).

El área de personal social, en Educación Primaria, tiene como finalidad contribuir al desarrollo integral del estudiante como persona autónoma, en búsqueda de la construcción de la identidad personal, social; así como proveer de conocimiento reflexivo acerca de las características sociales, culturales, geográficas, políticas y económicas que permitan, al estudiante, gestionar su propio aprendizaje, desarrollando el sentido de pertenencia (MINEDU, 2015). Asimismo, comprende la trascendencia del pasado para la construcción del futuro y la de su identidad cultural (Norambuena \& Le-Quesne, 2005) como ente, a fin de masificar el conocimiento de las múltiples manifestaciones que integran el patrimonio y la diversidad cultural peruana (Ministerio de Cultura, 2014).

El Ministerio de Educación del Perú ha elaborado una serie de documentos, denominados rutas de aprendizaje, en los cuales se da énfasis a la escuela democrática basada en la diversidad cultural y lingüística del estudiante (MINEDU, 2013) con el objetivo de que cada nińo conserve, revalore y aprenda a difundir su cultura, además de desarrollar procesos de aprendizaje que le permitan convivir en diversidad (Vargas, 2013) y ser activos en la protección y valoración del patrimonio arqueológico.

El diseño curricular de la Educación Primaria está basado en competencias que permite al estudiante adquirir competencias en diversas áreas del conocimiento y, para ello, son necesarias diversas herramientas con las cuales obtenga conocimiento e información actualizada que afiance su autonomía, autodesarrollo y automotivación (Ministerio de Educación, 2014). En el contexto del curso de Personal Social, existe la competencia "Construye Interpretaciones Históricas" (MINEDU, 2015), con tres capacidades: interpreta, críticamente, fuentes diversas; elabora explicaciones históricas que reconocen la relevancia de determinados procesos; comprende el tiempo histórico y emplea categorías temporales.

La penetración tecnológica en el Perú está en crecimiento. De 100 hogares, en 90 existe al menos un dispositivo tecnológico (INEI, 2015) y 18.9 millones de peruanos ya cuentan con celulares y 5.8 millones de estos usan teléfonos inteligentes, los mismos que marcan una tendencia de crecimiento (OSIPTEL, Encuesta Residencial de Servicios de Telecomunicaciones, 2014) - La conexión a Internet, en la telefonía móvil, fue de 11, 973,863 líneas (OSIPTEL, Reporte estadístico, 2015) y el 79\% de propietarios de teléfonos inteligentes tiene el sistemas operativo Android; el $26 \%$ el sistema operativo iOS (comScore, 2015). Los niños de 6 a 11 años acceden a Internet en un $32.2 \%$ y el $17.1 \%$ de la población de Educación Primaria accede a este recurso (INEI, 2015).

El uso de los videojuegos es común para los estudiantes y el desarrollo de juegos educativos en el Perú está en un periodo de inicio, mientras las aplicaciones de realidad aumentada se usan en las empresas (León, Jaico, \& Gao, 2015). Por tanto, la importancia de este trabajo radica en presentar el diseńo elaborado para el desarrollo de recursos digitales interactivos en apoyo al proceso de enseńanza-aprendizaje. 


\section{Recursos digitales interactivos para el apoyo de la educación}

El uso de herramientas de tecnología emergente como videojuegos y aplicaciones de realidad aumentada se fundamenta en que estas constituyen por sí mismas, elementos motivadores (Padilla et al., 2015) altamente aceptados por los estudiantes y, a la vez, proporcionan suficiente atractivo como para aumentar la motivación en los estudiantes, en contraposición con la desmotivación que se puede observar en la aulas cuando se utilizan, únicamente, las herramientas tradicionales (Padilla et al., 2015). Asimismo, las herramientas propuestas podrían utilizarse en sesiones de laboratorio como complemento a los enfoques tradicionales (Melero \& Hernández-Leo, 2013) o también usarse fuera de los ambientes formales de enseñanza para reforzar los conceptos aprendidos en el aula como complemento educativo para que el aprendizaje sea duradero y además lúdico.

Los recursos digitales interactivos diseñados, específicamente, para enseñar; involucran a estudiantes, profesores, especialistas, investigadores además del equipo desarrollador, quienes en su ejecución se convierten en instrumentos de enseñanza con mucha potencialidad que utilizados de forma complementaria con otros métodos de instrucción tradicionales, pueden conseguir que la motivación de los estudiantes no decaiga a medida que se progresa en la materia estudiada (Padilla et al., 2015).

El uso de los recursos digitales interactivos ha adquirido un fuerte impulso gracias a la reducción de costos de los equipos, y la fuerte penetración de los dispositivos móviles que han influido en la deslocalización de las tecnologías (Cabero \& Barroso, 2016) y el uso para potenciar el proceso de enseñanza aprendizaje. Los videojuegos educativos representan, en la actualidad, una de las vías más directas para que los niños puedan comprender sobre su cultura y así, mejorar el proceso de aprendizaje en muchos aspectos como el aumento de la motivación de los estudiantes (Morales, 2009).

La realidad aumentada ha sido usada para el desarrollo de diversas aplicaciones en museos, archivos históricos, monumentos, galerías de arte, sitios arqueológicos y parques temáticos, en los cuales el usuario interactúa con información adicional y contextualizada de los objetos, obras y lugares (Alegría, 2015). Estas aplicaciones han convertido a estos sitios en máquinas del tiempo, dentro de las cuales se puede viajar con los ojos y la mente acompañados de un pensamiento y reflexión crítica que convierta a estos sitios en una verdadera "escuela alternativa".

La persistencia de la preservación de la memoria colectiva es factor importante para la identidad, conciencia de la historia personal y colectiva (Sarracino, 2014). Los espacios virtuales para la enseñanza del patrimonio arqueológico tienen múltiples potencialidades, desde una perspectiva didáctica que permita un acercamiento a la historia, un concepto de aprendizaje práctico (hands on), el pensamiento (minds on) y el sentimiento (hearts on), puesto que conecta la materialidad con la resolución de problemas y la empatía histórica. Aquí es dónde reside su potencial educativo y la necesidad de incluir estas enseñanzas en la escuela (Vicent, Rivero, \& Feliu, 2015) para aumentar las teorías desarrolladas en el aula.

Los recursos tecnológicos y/o digitales posibilitan acercar la realidad del estudiante a los conocimientos, de manera natural, por ser parte del mundo en el que los nińos están inmersos gran parte del día.

Cultiventura agrupa los recursos digitales de videojuegos y aplicaciones de realidad aumentada de la cultura Mochica y Chimú, (Figura 1). Para dicha cultura,se desarrollaron videojuegos $2 \mathrm{D}, 3 \mathrm{D}$ y aplicaciones de realidad aumentada (Figuras 2, 3,4). 


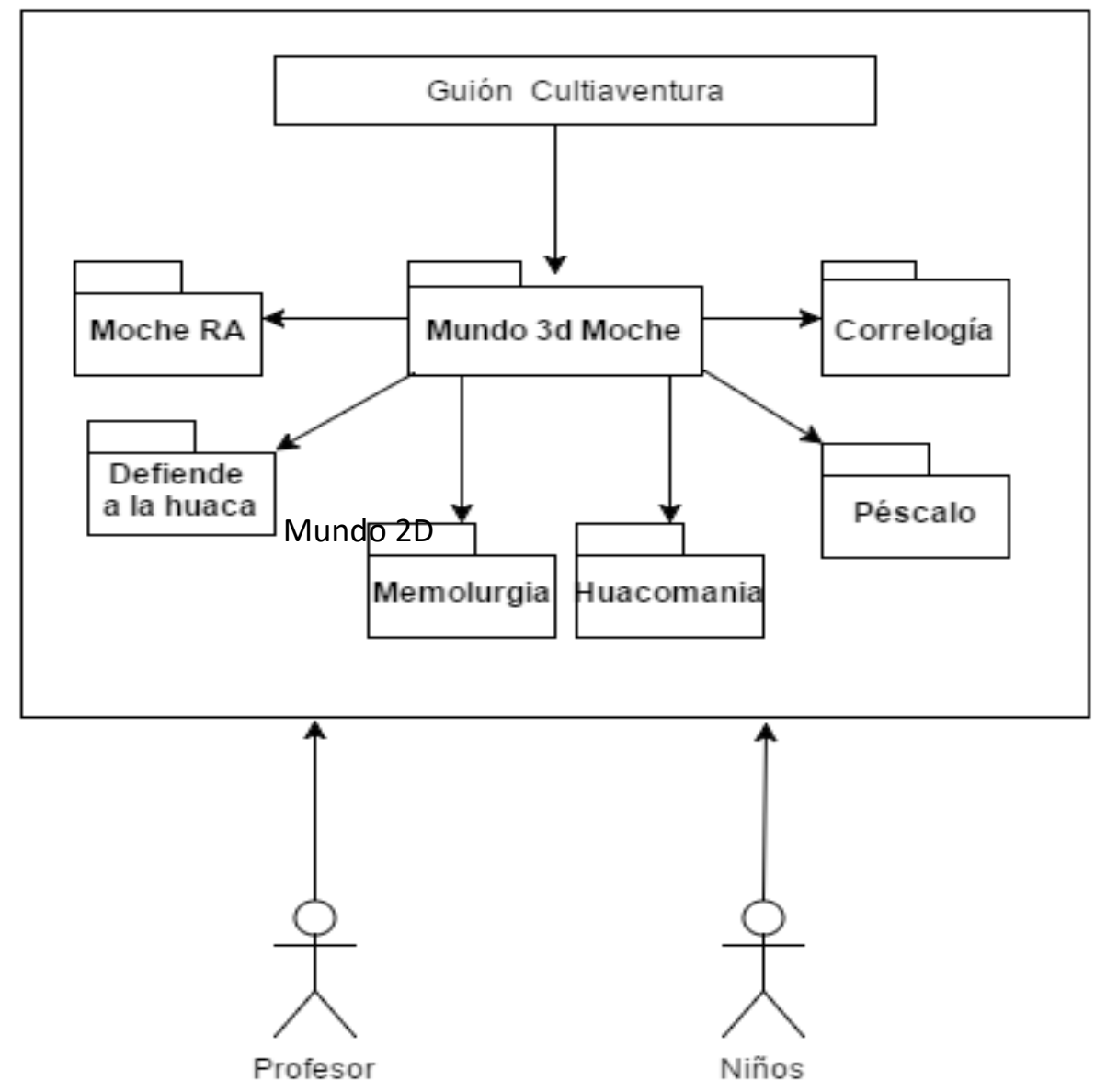

Figura 1. Recursos digitales para la cultura Moche
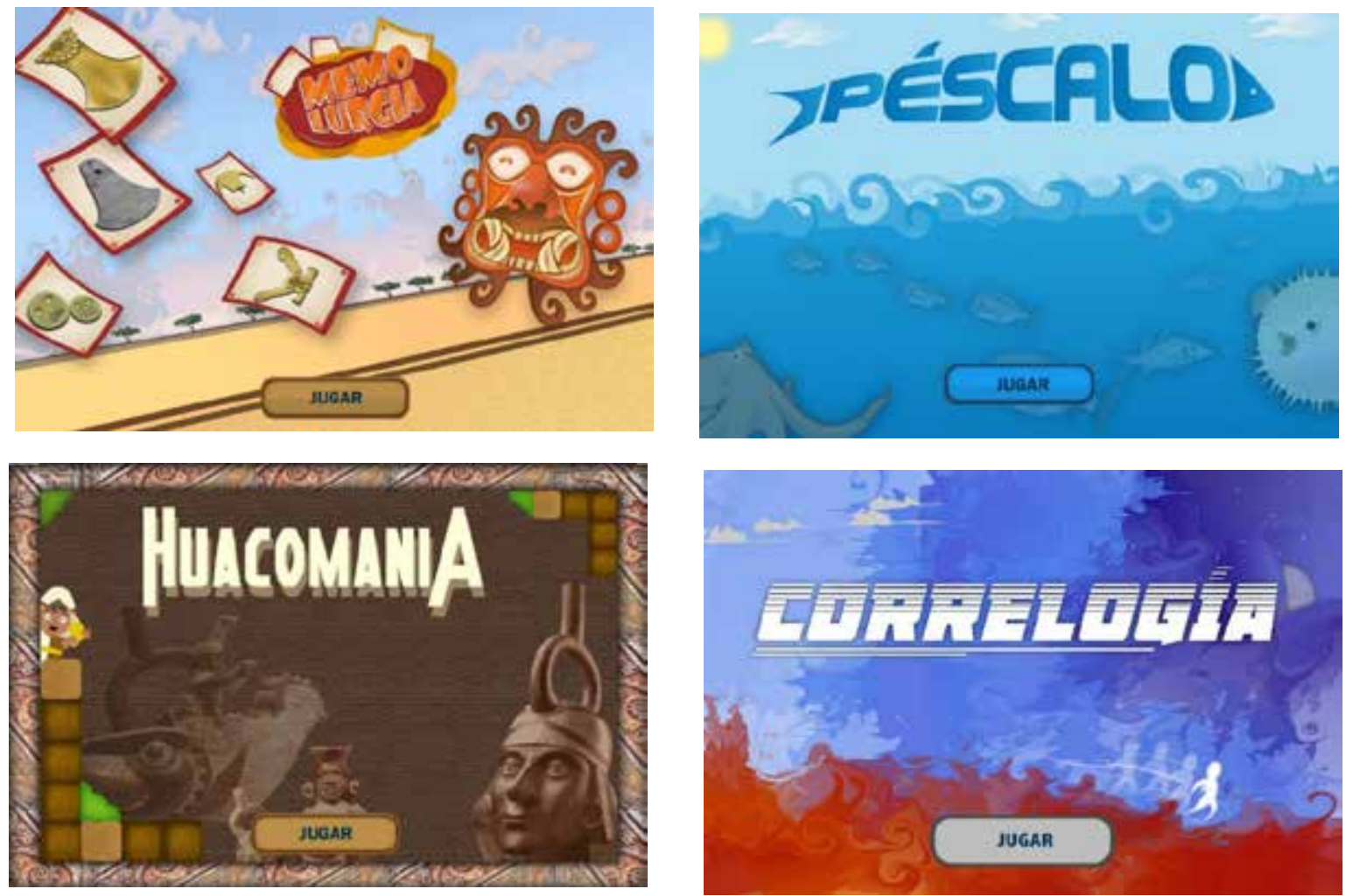

Figura 2. Recurso - Juegos 2d de la cultura Moche 

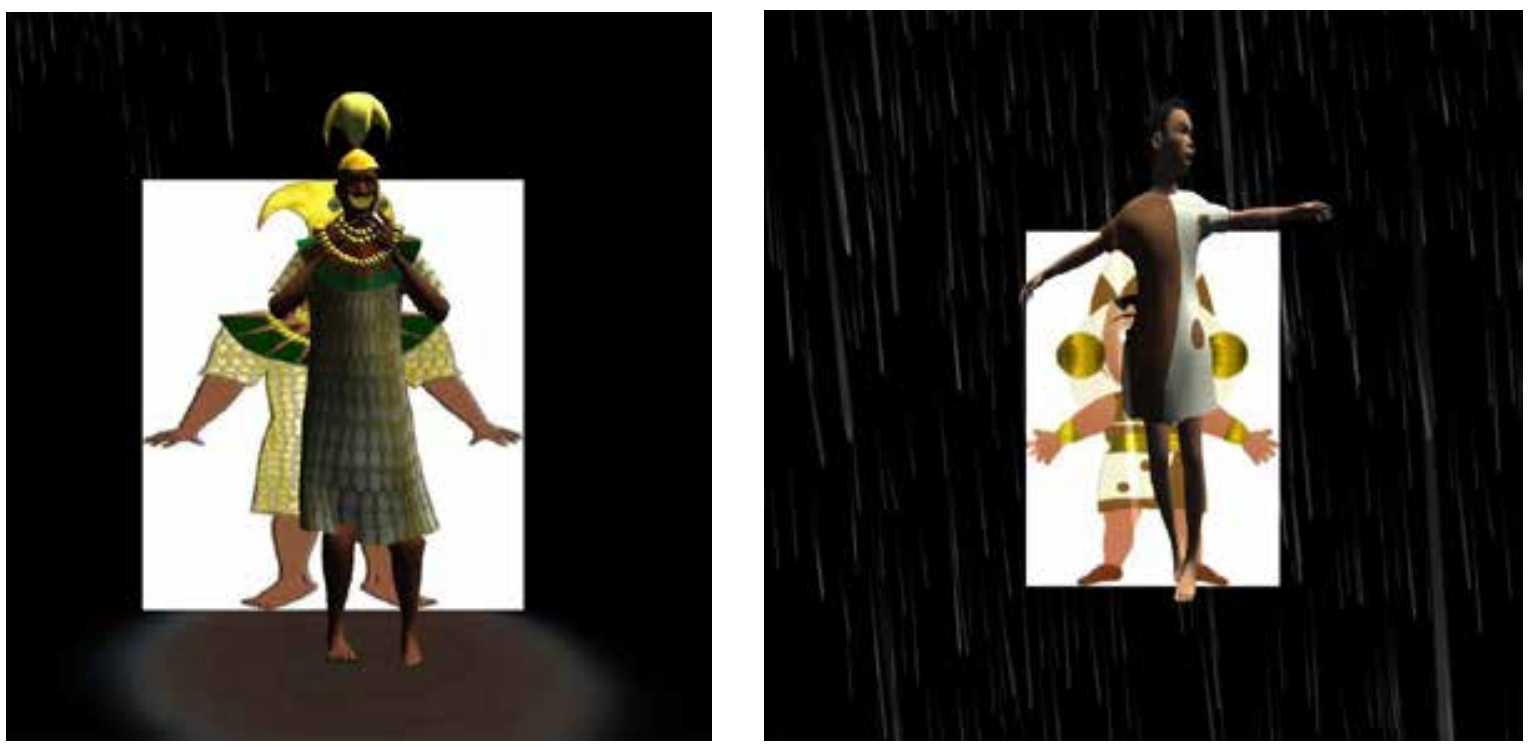

Figura 3: Recurso de Realidad aumentad Señor de Sipán y Nińo Moche

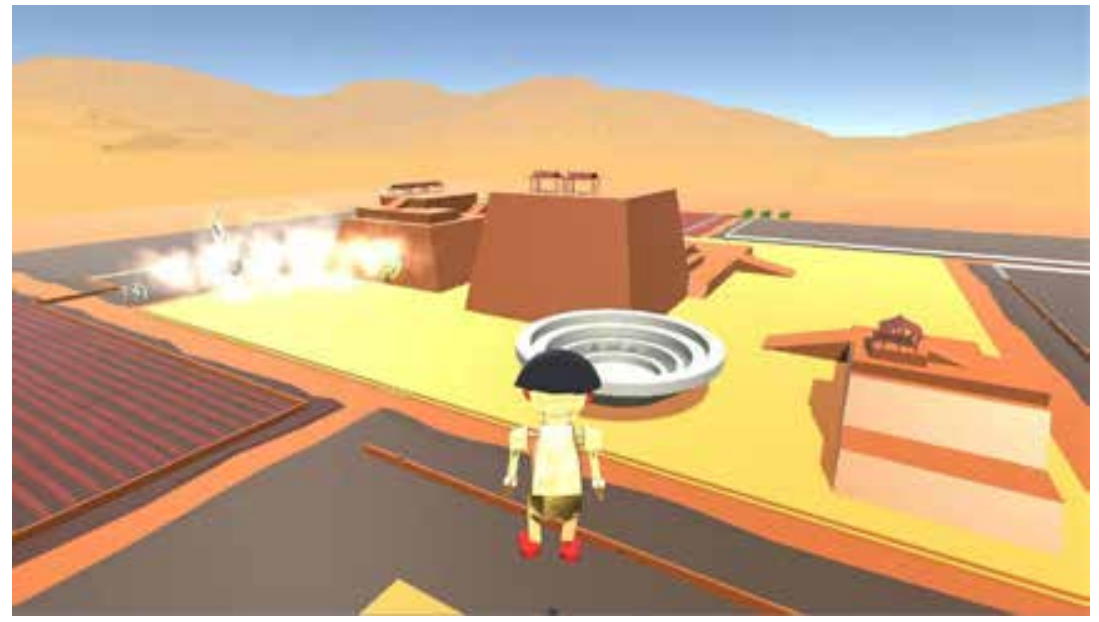

Figura 4: Vista 3D Huaca Rajada Moche

\section{Diseño del entorno educativo}

Una de las premisas importantes, a la hora de diseñar un recurso lúdico educativo, consiste en que el contenido educativo esté camuflado dentro de los propios elementos del recurso, a fin de fomentar el éxito del aprendizaje, (Soriano, González, \& Gutiérrez, 2015). Dicho recurso debe centrarse en resolver problemas del mundo real, activar conocimientos previos e integrarlos en la vida diaria.

La producción de recursos digitales, altamente interactivas, como apoyo en el proceso de enseñanza -aprendizaje de la Arqueología, exige una metodología para la transforma- ción, desde la oportunidad de dar a conocer los hallazgos realizados por científicos y brindar una herramienta interactiva, motivadora y divertida, que provoque el aprendizaje y la identificación como consecuencia directa de jugar e interactuar, tanto a estudiantes como a profesores. La metodología aplicada se inicia con el mapeo de la competencia "Construye interpretaciones históricas" y luego las traza con las funcionalidades del recurso digital. Una vez realizadas, se ejecuta el proceso de construcción de los recursos digitales.

\section{Mapeo de las competencias}

El mapeo de las competencias identifica las tres capacidades de las competencias en rela- 
ción con sus capacidades e ideas fuerza, además de los indicadores de cada una de ellas Fuente: (MINEDU, 2015).

1. Interpreta, críticamente, diversas fuentes:

- Reconoce la diversidad de las mismas y su diferente utilidad para abordar un tema histórico.

- Ubica las fuentes en su contexto y comprende la perspectiva al interior de las fuentes.

- Reconoce, describe e interpreta la información que la fuente transmite.

2. Elabora explicaciones históricas en las que reconoce la relevancia de determinados procesos:

- Identifica múltiples causas y consecuencias.

- Construye explicaciones históricas sobre problemas históricos, a partir de evidencias.

- Reconoce la relevancia histórica y se reconoce como sujeto histórico.

- Comprende la perspectiva de los protagonistas.
- Emplea vocabulario histórico.

3. Comprende el tiempo histórico y emplea categorías temporales:

- Reconoce y emplea convenciones temporales.

- Comprende la sucesión y la similitud.

- Registra duración y ritmos en la historia.

- Analiza cambios y permanencias a lo largo de la historia.

\section{Modelo ágil para la construcción de recur- sos digitales}

Está estructurado, a fin de proporcionar recursos tecnológicos e interactivos como videojuegos, aplicaciones de realidad aumentada y realidad virtual. El modelo permite identificar las características y funcionalidades del recurso digital, dividirlo y planificar su desarrollo por partes de acuerdo con la necesidad y capacidad del equipo, Figura 1. Cada división se subdivide en partes más pequeńas. Concluido este proceso de desarrollo, se integra.
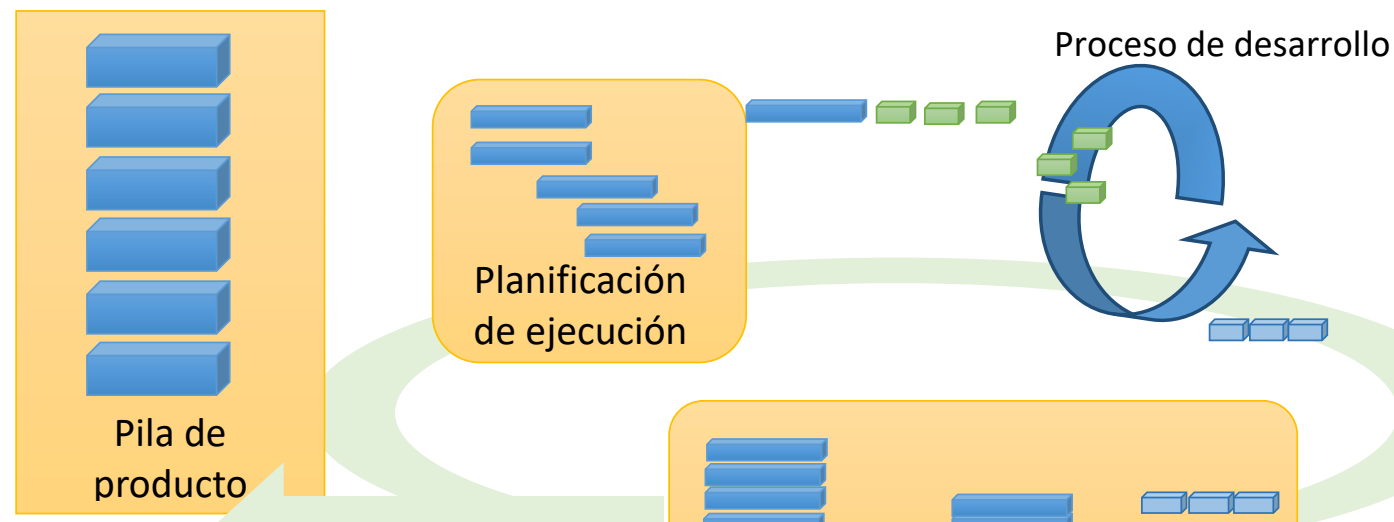

producto
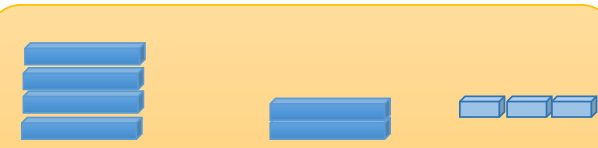

Integración

Figura 5. Modelo ágil para desarrollo de recursos digitales interactivos 
El modelo soporta el desarrollo interactivo e incremental de los recursos digitales. Esto significa que se inicia el proceso con las funcionalidades básicas del recurso y luego se incrementan durante el proceso de construcción.

1. Concepción del recurso:

- El docente ubica el contexto y la necesidad de conocimiento por difundir.

- El equipo concibe la idea inicial del recurso por crear.

2. Funcionalidades y reglas de negocio:

- El profesor de historia provee los conceptos necesarios para la creación del recurso.

- El psicólogo y arqueólogo analizan el diseño del concepto inicial.

- El analista de recurso define las funcionalidades y reglas para la construcción del recurso.

3. Diseño:

- El diseñador de recurso crea la arquitectura del recurso (diversas vistas de acuerdo con el equipo para el desarrollo del recurso).

- El diseñador de música compone la música de acuerdo con cada recurso.

- El diseñador de interfaz diseña los objetos $2 \mathrm{~d}$ y $3 \mathrm{~d}$, además de las texturas.
4. Desarrollo:

- El creador de animaciones genera las animaciones exigidas por el recurso.

- El compositor musical genera sonidos y música.

- El programador desarrolla los códigos que exige la lógica del recurso y genera librerías y componentes de software.

5. Pruebas:

- El encargado de calidad realiza las pruebas unitarias por cada funcionalidad del recurso creado. Se prueba la funcionalidad, experiencia del usuario, arte conceptual, armonía, audiovisual, trazabilidad educativa (Cultiventura incluye la trazabilidad histórica por tratarse de recursos educativos, que comprende parte de la Arqueología peruana).

- En caso de no haber observaciones, se realizan las pruebas finales del recurso, que son validadas por el arqueólogo, profesor, psicólogo e investigador.

- En caso de haber observaciones, se regresa a la actividad inicial.

\section{Producto final:}

Todo este proceso se repite para cada incremento del recurso digital. El número de incrementos está directamente relacionado con el número de funcionalidades definidas para cada recurso digital y la complejidad que involucra. 


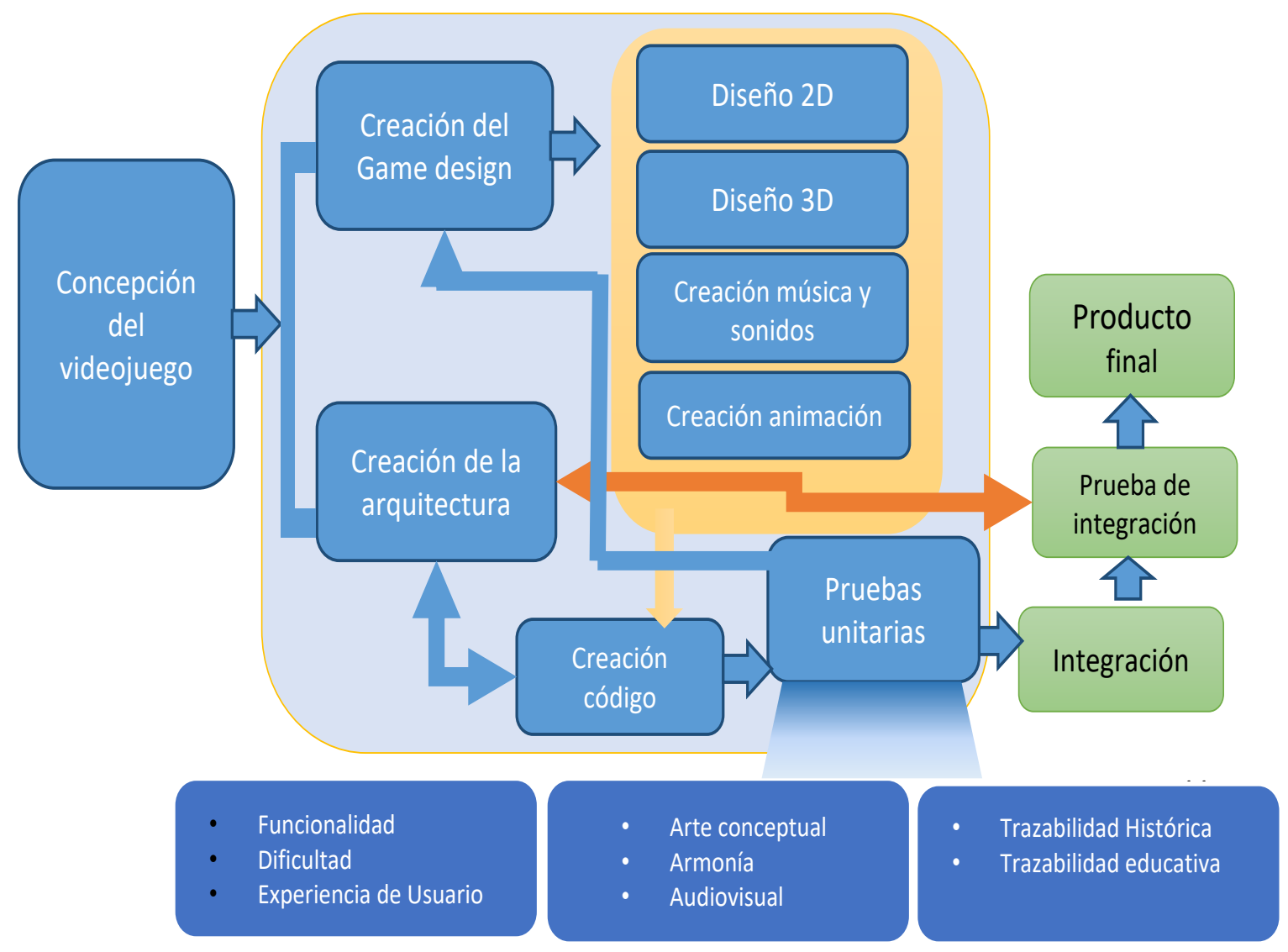

Figura 6. Proceso de desarrollo de los recursos digitales interactivos

\section{Resultados}

Como resultado del diseño aplicado para la creación de los recursos digitales, a fin de complementar la enseńanza -aprendizaje de la cultura Moche se desarrolló el guion de Cultiventura, en el cual se incluyen los componentes principales, necesarios para crear los recursos que permitirán a los niños y profesores realizar el proceso de enseñanza - aprendizaje de la cultura Moche.

Se desarrollaron recursos digitales $2 \mathrm{D}$ en función de videojuegos para ser ejecutados en computadoras o dispositivos móviles, recursos digitales 3D (espacios virtuales) que pueden ser activados en Internet o en una computadora personal.

Además, se obtuvo las tablas de trazabilidad del modelo de competencias (Tabla 1, 2) y el modelo de desarrollo de recursos digitales, en los que se pueden identificar las capacidades definidas en el Área de Personal Social, mediante los indicadores para el desarrollo de cada recurso digital. Luego, estos sirven para que en el proceso de implantación se puedan medir con los usuarios. 
Tabla 1

Trazabilidad de las competencias en el modelo para el desarrollo de los mini juegos MOCHICA

\begin{tabular}{|c|c|c|c|c|c|}
\hline \multicolumn{6}{|c|}{ Área de Personal Social } \\
\hline \multicolumn{2}{|c|}{ Competencia } & \multicolumn{4}{|c|}{ Construyendo interpretaciones históricas } \\
\hline \multirow{3}{*}{$\begin{array}{c}\text { Capacidades } \\
\text { del área }\end{array}$} & \multirow{3}{*}{$\begin{array}{l}\text { Indicadores } \\
\text { pedagógicos }\end{array}$} & \multicolumn{4}{|c|}{ MUNDO 2D } \\
\hline & & $\begin{array}{l}\text { Mini juego } 1 \\
\text { Memolurgia }\end{array}$ & $\begin{array}{l}\text { Mini juego } 2 \\
\text { Huacomanía }\end{array}$ & $\begin{array}{l}\text { Mini juego } 3 \\
\text { Péscalo }\end{array}$ & $\begin{array}{l}\text { Mini juego } 4 \\
\text { Correología }\end{array}$ \\
\hline & & $\begin{array}{l}\text { Indicadores } \\
\text { del juego }\end{array}$ & $\begin{array}{l}\text { Indicadores } \\
\text { del juego }\end{array}$ & $\begin{array}{l}\text { Indicadores del } \\
\text { juego }\end{array}$ & $\begin{array}{l}\text { Indicadores del } \\
\text { juego }\end{array}$ \\
\hline \multirow{3}{*}{$\begin{array}{l}\text { Interpreta } \\
\text { críticamente } \\
\text { fuentes } \\
\text { diversas. }\end{array}$} & $\begin{array}{l}\text { Reconoce la } \\
\text { diversidad } \\
\text { de fuentes y } \\
\text { su diferente } \\
\text { utilidad } \\
\text { para abordar } \\
\text { un tema } \\
\text { histórico. }\end{array}$ & $\begin{array}{c}\text { Identifica los } \\
\text { ornamentos } \\
\text { encontrados en } \\
\text { las tumbas del } \\
\text { Seńor de Sipán } \\
\text { como fuentes } \\
\text { materiales } \\
\text { para el } \\
\text { conocimiento } \\
\text { de la historia. }\end{array}$ & $\begin{array}{l}\text { Identifica } \\
\text { huacos o } \\
\text { ceramios } \\
\text { moche } \\
\text { como fuente } \\
\text { material para } \\
\text { el aprendizaje } \\
\text { de la historia } \\
\text { y arqueología. }\end{array}$ & $\begin{array}{l}\text { Identifica } \\
\text { los recursos } \\
\text { ictiológicos } \\
\text { moche, como } \\
\text { base de la } \\
\text { alimentación } \\
\text { y forma de } \\
\text { vida de sus } \\
\text { habitantes. }\end{array}$ & $\begin{array}{l}\text { Identifican los } \\
\text { personajes de } \\
\text { la mitología } \\
\text { moche a través } \\
\text { de las imágenes } \\
\text { presentadas. }\end{array}$ \\
\hline & $\begin{array}{l}\text { Ubica las } \\
\text { fuentes en su } \\
\text { contexto y } \\
\text { comprende } \\
\text { la perspectiva } \\
\text { detrás de la } \\
\text { fuente. }\end{array}$ & $\begin{array}{c}\text { Hace uso de } \\
\text { una fuente } \\
\text { virtual como } \\
\text { el juego de } \\
\text { cartas sobre } \\
\text { la orfebrería } \\
\text { moche para } \\
\text { conocer una } \\
\text { manifestación } \\
\text { cultural }\end{array}$ & $\begin{array}{l}\text { Hace uso } \\
\text { de la fuente } \\
\text { virtual como } \\
\text { el juego de } \\
\text { explorados } \\
\text { en busca } \\
\text { de huacos } \\
\text { moche para } \\
\text { conocer su } \\
\text { cerámica. }\end{array}$ & $\begin{array}{l}\text { Hace uso de } \\
\text { una fuente } \\
\text { virtual: mundo } \\
\text { marino moche } \\
\text { para obtener } \\
\text { información } \\
\text { sobre las } \\
\text { actividades } \\
\text { económicas de } \\
\text { la cultura. }\end{array}$ & $\begin{array}{l}\text { Hace uso de una } \\
\text { fuente virtual: } \\
\text { mitología } \\
\text { moche para } \\
\text { obtener } \\
\text { información la } \\
\text { religión de esta } \\
\text { cultura. }\end{array}$ \\
\hline & $\begin{array}{l}\text { Reconoce, } \\
\text { describe e } \\
\text { interpreta la } \\
\text { información } \\
\text { que la fuente } \\
\text { transmite. }\end{array}$ & $\begin{array}{c}\text { Conoce la } \\
\text { importancia de } \\
\text { la metalurgia } \\
\text { moche. }\end{array}$ & $\begin{array}{c}\text { Conoce la } \\
\text { importancia } \\
\text { de la cerámica } \\
\text { moche. }\end{array}$ & $\begin{array}{c}\text { Conoce la } \\
\text { importancia } \\
\text { de la pesca } \\
\text { como actividad } \\
\text { económica de la } \\
\text { cultura moche. }\end{array}$ & $\begin{array}{c}\text { Conoce la } \\
\text { importancia de } \\
\text { los mitología } \\
\text { dentro de la } \\
\text { cosmovisión de } \\
\text { la cultura moche }\end{array}$ \\
\hline $\begin{array}{l}\text { Comprende } \\
\text { el tiempo } \\
\text { histórico } \\
\text { y emplea } \\
\text { categorías } \\
\text { temporales. }\end{array}$ & $\begin{array}{l}\text { Comprende } \\
\text { cambios y } \\
\text { permanencias } \\
\text { a lo largo de } \\
\text { la historia. }\end{array}$ & $\begin{array}{c}\text { Conoce la } \\
\text { importancia } \\
\text { sociopolítica } \\
\text { de la cultura al } \\
\text { identifica los } \\
\text { ornamentos } \\
\text { usados por } \\
\text { los miembros } \\
\text { de la élite } \\
\text { gobernante } \\
\text { de la sociedad } \\
\text { moche. }\end{array}$ & $\begin{array}{l}\text { Conoce la } \\
\text { arquitectura } \\
\text { monumental } \\
\text { moche e } \\
\text { identifica la } \\
\text { importancia } \\
\text { de las huacas } \\
\text { como centros } \\
\text { religiosos de } \\
\text { culto a sus } \\
\text { dioses. }\end{array}$ & $\begin{array}{l}\text { Conoce las } \\
\text { actividades } \\
\text { económicas, } \\
\text { específicamente } \\
\text { la pesca de la } \\
\text { cultura moche } \\
\text { a través de las } \\
\text { representaciones } \\
\text { encontradas en } \\
\text { su cerámica e } \\
\text { iconografía. }\end{array}$ & $\begin{array}{l}\text { Conoce la } \\
\text { religión moche } \\
\text { a través de } \\
\text { los personajes } \\
\text { mitológicos } \\
\text { encontrados en } \\
\text { las diferentes } \\
\text { manifestaciones } \\
\text { culturales y } \\
\text { artísticas. }\end{array}$ \\
\hline
\end{tabular}




\begin{tabular}{|c|c|c|c|c|c|}
\hline $\begin{array}{c}\text { Elabora } \\
\text { explicaciones } \\
\text { históricas } \\
\text { reconociendo } \\
\text { la relevancia } \\
\text { de } \\
\text { determinados } \\
\text { procesos. }\end{array}$ & $\begin{array}{l}\text { Construye } \\
\text { explicaciones } \\
\text { históricas a } \\
\text { problemas } \\
\text { históricos } \\
\text { a partir de } \\
\text { evidencias. }\end{array}$ & $\begin{array}{l}\text { Difunde las } \\
\text { técnicas de } \\
\text { extracción } \\
\text { de minerales } \\
\text { y métodos } \\
\text { de fundición } \\
\text { empleados en } \\
\text { la metalurgia } \\
\text { para la } \\
\text { fabricación de } \\
\text { ornamentos, } \\
\text { armas y } \\
\text { herramientas, } \\
\text { objetos sacros, } \\
\text { religiosos y } \\
\text { militares. }\end{array}$ & $\begin{array}{c}\text { Difunde } \\
\text { las técnicas } \\
\text { empleadas en } \\
\text { la cerámica } \\
\text { pictórica y } \\
\text { decorativa. }\end{array}$ & $\begin{array}{c}\text { Destaca } \\
\text { importancia } \\
\text { de la pesca } \\
\text { como actividad } \\
\text { económica } \\
\text { básica y los } \\
\text { productos que } \\
\text { extraían. }\end{array}$ & $\begin{array}{c}\text { Reconoce la } \\
\text { importancia } \\
\text { de la religión } \\
\text { moche como } \\
\text { parte de la } \\
\text { forma de vida de } \\
\text { sus habitantes. }\end{array}$ \\
\hline
\end{tabular}


DisEÑO DE ENTORNOS EDUCATIVOS BASADOS EN APLICACIONES INTERACTIVAS DE REALIDAD AUMENTADA Y VIDEOJUEGOS PARA EL APRENDIZAJE ACTIVO DE LA ARQUEOLOGÍA

Tabla 2

Trazabilidad de las competencias en el modelo para el desarrollo las aplicaciones de realidad aumentada MOCHICA

\begin{tabular}{|c|c|c|c|c|c|}
\hline \multicolumn{6}{|c|}{ Área de Personal Social } \\
\hline \multicolumn{2}{|c|}{ Competencia } & \multirow{2}{*}{\multicolumn{4}{|c|}{ Construyendo interpretaciones históricas }} \\
\hline \multirow{3}{*}{$\begin{array}{l}\text { Capacidades } \\
\text { del área }\end{array}$} & \multirow{3}{*}{$\begin{array}{l}\text { Indicadores } \\
\text { pedagógicos }\end{array}$} & \multicolumn{2}{|c|}{ MUNDO 2D } & & \\
\hline & & $\begin{array}{l}\text { Realidad } \\
\text { aumentada } \\
\text { Memolurgia }\end{array}$ & $\begin{array}{c}\text { Realidad } \\
\text { aumentada } \\
\text { Huacomanía }\end{array}$ & $\begin{array}{l}\text { Realidad } \\
\text { aumentada } \\
\text { Péscalo }\end{array}$ & $\begin{array}{l}\text { Realidad } \\
\text { aumentada } \\
\text { Correlogía }\end{array}$ \\
\hline & & $\begin{array}{c}\text { Indicadores de } \\
\text { RA }\end{array}$ & $\begin{array}{c}\text { Indicadores de } \\
\text { RA }\end{array}$ & \begin{tabular}{|c} 
Indicadores de \\
RA \\
\end{tabular} & $\begin{array}{c}\text { Indicadores } \\
\text { de RA }\end{array}$ \\
\hline \multirow{3}{*}{$\begin{array}{l}\text { Interpreta } \\
\text { críticamente } \\
\text { fuentes } \\
\text { diversas. }\end{array}$} & $\begin{array}{l}\text { Reconoce la } \\
\text { diversidad } \\
\text { de fuentes y } \\
\text { su diferente } \\
\text { utilidad } \\
\text { para abordar } \\
\text { un tema } \\
\text { histórico. }\end{array}$ & $\begin{array}{c}\text { Identifica, } \\
\text { categoriza y } \\
\text { ordena los } \\
\text { ornamentos } \\
\text { encontrados en } \\
\text { las tumbas de } \\
\text { Señor de Sipán } \\
\text { presentados } \\
\text { como fuentes } \\
\text { materiales } \\
\text { para el } \\
\text { conocimiento } \\
\text { de la metalurgia } \\
\text { moche. }\end{array}$ & $\begin{array}{l}\text { Selecciona, } \\
\text { organiza y } \\
\text { construye el } \\
\text { rompecabezas } \\
\text { de un huaco o } \\
\text { ceramio moche } \\
\text { como fuente } \\
\text { material para } \\
\text { el aprendizaje } \\
\text { de la Historia y } \\
\text { Arqueología. }\end{array}$ & $\begin{array}{l}\text { Observa y } \\
\text { asocia los } \\
\text { recursos } \\
\text { ictiológicos } \\
\text { presentados con } \\
\text { las actividades } \\
\text { económicas de } \\
\text { los moche. }\end{array}$ & $\begin{array}{l}\text { Observa, } \\
\text { conoce e } \\
\text { identifica } \\
\text { Los } \\
\text { personajes } \\
\text { de la } \\
\text { mitología } \\
\text { moche. }\end{array}$ \\
\hline & $\begin{array}{l}\text { Ubica las } \\
\text { fuentes en su } \\
\text { contexto y } \\
\text { comprende } \\
\text { la perspectiva } \\
\text { detrás de la } \\
\text { fuente. }\end{array}$ & $\begin{array}{l}\text { Analiza, } \\
\text { reconoce y } \\
\text { relaciona los } \\
\text { ornamentos } \\
\text { utilizados } \\
\text { por el Seńor } \\
\text { de Sipán y } \\
\text { refuerza los } \\
\text { conocimientos } \\
\text { aprendidos } \\
\text { en el mini } \\
\text { juego virtual, } \\
\text { Memolurgia. }\end{array}$ & $\begin{array}{l}\text { Reconoce } \\
\text { los ceramios } \\
\text { moche } \\
\text { relaciona la } \\
\text { información } \\
\text { presentada } \\
\text { y compara } \\
\text { los objetos } \\
\text { presentados. }\end{array}$ & $\begin{array}{c}\text { Enfoca los } \\
\text { elementos } \\
\text { del mundo } \\
\text { marino moche y } \\
\text { selecciona cada } \\
\text { uno de ellos } \\
\text { para obtener } \\
\text { información al } \\
\text { respecto. }\end{array}$ & $\begin{array}{l}\text { Selecciona } \\
\text { los } \\
\text { personajes } \\
\text { mitológicos } \\
\text { moche y } \\
\text { destaca la } \\
\text { importancia } \\
\text { de cada uno } \\
\text { de ellos. }\end{array}$ \\
\hline & $\begin{array}{l}\text { Reconoce, } \\
\text { describe e } \\
\text { interpreta la } \\
\text { información } \\
\text { que la fuente } \\
\text { transmite. }\end{array}$ & $\begin{array}{l}\text { Selecciona y } \\
\text { discrimina los } \\
\text { ornamentos } \\
\text { presentados. } \\
\text { Los reconoce } \\
\text { y ubica como } \\
\text { parte del } \\
\text { atuendo del } \\
\text { Señor de Sipán. }\end{array}$ & $\begin{array}{c}\text { Consolida la } \\
\text { información } \\
\text { sobre la } \\
\text { importancia } \\
\text { de la cerámica } \\
\text { moche al } \\
\text { reconocer } \\
\text { los diferentes } \\
\text { ceramios } \\
\text { presentados. }\end{array}$ & $\begin{array}{l}\text { Despliega interés } \\
\text { sobre la pesca } \\
\text { como actividad } \\
\text { económica de la } \\
\text { cultura moche. }\end{array}$ & $\begin{array}{c}\text { Interpreta la } \\
\text { información } \\
\text { que se le } \\
\text { brinda, } \\
\text { respecto a } \\
\text { la mitología } \\
\text { moche. }\end{array}$ \\
\hline
\end{tabular}




\begin{tabular}{|c|c|c|c|c|c|}
\hline $\begin{array}{l}\text { Comprende } \\
\text { el tiempo } \\
\text { histórico } \\
\text { y emplea } \\
\text { categorías } \\
\text { temporales. }\end{array}$ & $\begin{array}{l}\text { Comprende } \\
\text { cambios y } \\
\text { permanencias } \\
\text { a lo largo de } \\
\text { la historia. }\end{array}$ & $\begin{array}{l}\text { Reconoce la } \\
\text { importancia } \\
\text { sociopolítica } \\
\text { de la cultura; } \\
\text { identifica, } \\
\text { selecciona y } \\
\text { compara los } \\
\text { ornamentos } \\
\text { usados por } \\
\text { los miembros } \\
\text { de la élite } \\
\text { gobernante } \\
\text { de la sociedad } \\
\text { moche. }\end{array}$ & $\begin{array}{l}\text { Valora la } \\
\text { arquitectura } \\
\text { monumental } \\
\text { moche y } \\
\text { reconoce la } \\
\text { importancia } \\
\text { de las huacas } \\
\text { como centros } \\
\text { religiosos de } \\
\text { culto a sus } \\
\text { dioses. }\end{array}$ & $\begin{array}{c}\text { Analiza y } \\
\text { reconoce los } \\
\text { elementos } \\
\text { del mundo } \\
\text { marino moche } \\
\text { y los valora } \\
\text { como grandes } \\
\text { navegantes. }\end{array}$ & $\begin{array}{c}\text { Reconoce } \\
\text { y valora los } \\
\text { personajes } \\
\text { mitológicos } \\
\text { moche. }\end{array}$ \\
\hline $\begin{array}{c}\text { Elabora } \\
\text { explicaciones } \\
\text { históricas } \\
\text { reconociendo } \\
\text { la relevancia de } \\
\text { determinados } \\
\text { procesos. }\end{array}$ & $\begin{array}{l}\text { Construye } \\
\text { explicaciones } \\
\text { históricas a } \\
\text { problemas } \\
\text { históricos } \\
\text { a partir de } \\
\text { evidencias. }\end{array}$ & $\begin{array}{c}\text { Interioriza } \\
\text { las técnicas } \\
\text { de extracción } \\
\text { de minerales } \\
\text { y métodos } \\
\text { de fundición } \\
\text { empleados en la } \\
\text { metalurgia para } \\
\text { la fabricación } \\
\text { de ornamentos, } \\
\text { armas y } \\
\text { herramientas, } \\
\text { objetos sacros, } \\
\text { religiosos y } \\
\text { militares. }\end{array}$ & $\begin{array}{l}\text { Argumenta } \\
\text { en base a sus } \\
\text { conocimientos } \\
\text { adquiridos } \\
\text { las técnicas } \\
\text { empleadas en } \\
\text { la cerámica } \\
\text { pictórica y } \\
\text { decorativa. }\end{array}$ & $\begin{array}{l}\text { Sobre la base de } \\
\text { su observación y } \\
\text { análisis, destaca } \\
\text { la importancia } \\
\text { de la pesca } \\
\text { como actividad } \\
\text { económica } \\
\text { básica. }\end{array}$ & $\begin{array}{c}\text { A base de la } \\
\text { información } \\
\text { presentada, } \\
\text { reconoce la } \\
\text { importancia } \\
\text { de la } \\
\text { mitología } \\
\text { como parte } \\
\text { de la visión } \\
\text { del mundo } \\
\text { religioso } \\
\text { moche }\end{array}$ \\
\hline
\end{tabular}

\section{Conclusiones}

Se ha logrado diseñar el proceso de creación de recursos digitales interactivos, en concordancia, con el modelo de competencias "Construye Interpretaciones Históricas" del Ministerio de Educación peruano como soporte para la creación de recursos de la enseñanza- aprendizaje de Arqueología en Educación Primaria.

Se ha probado que el diseño permite crear recursos digitales de manera trazable con las normativas del aprendizaje por competencias y alineadas a las rutas de aprendizaje del Ministerio de Educación del Perú.
El diseño explicado en este trabajo, permite crear recursos digitales de manera incremental alineados al aprendizaje por competencias que posibiliten a los investigadores validar las funcionalidades y características de los mismos durante el proceso de desarrollo.

El diseño presentado admite el incremento de otros recursos digitales al modelo, sin perder la trazabilidad con las competencias que se desean proporcionar al estudiante.

El diseño facilita la creación de recursos digitales tanto para un entorno educativo como fuera de él. 


\section{Referencias}

Alegría, M. (2015). Aplicaciones de la realidad aumentada en el ámbito de la enseñanza superior. Diseño de un proyecto piloto. Cuadernos de Gestión de Información, 5(1), 18-35.

Cabero, J. \& Barroso, J. (enero, 2016). Posibilidades educativas de la Realidad Aumentada. NEW Approaches In Educational Research, 5(1), 46-52. doi:10.7821/naer2016.1.140

comScore (2015). IMS mobile in latam. Recuperado de http://www.imscorporate.com/news/Estudios-comScore/ IMS-Mobile-Study-Enero2015.pdf

INEI. (2015). Estadisticas de las Tecnologías . Recuperado de https://www.inei.gob. pe/media/MenuRecursivo/boletines/ informe-tecnico_tecnologias-informacion-jul-ago-set2015.pdf

Innóvate Perú. (15, Agosto, 2016). Convocatorias. Recuperado de http://www. fincyt.gob.pel

León, N., Jaico, C. \& Gao, J. (2015). Método de inclusión de herramienta de realidad aumentada como apoyo al proceso de enseñanza-aprendizaje del curso de Personal Social en educación. Lima, Perú: USMP.

Melero, J. \& Hernández-Leo, D. (2013). A Model for the Design of Puzzle-based Games Including Virtual and Physical Objects. Educational Technology \& Society, 17(3), 192-207.

MINEDU. (2013). Rutas del Aprendizaje. Lima: Corporación Gráfica Navarrete S.A.

MINEDU. (2015). Resolución Ministerial $N^{\circ}$ 199-2015. Lima, Perú.
MINEDU. (2015). Rutas de aprendizaje 2015 ¿Qué y cómo aprenden nuestros estudiantes? Lima: Amauta Impresiones Comerciales S.A.C.

Ministerio de Cultura. (2014). Resolución Ministerial $N^{\circ} 160-2014$. Lima, Perú.

Ministerio de Educación. (17, febrero, 2014). Enfoque por competencias y Rutas del aprendizaje [online]. Recuperado de PeruEduca Sistema digital para el aprendizaje: http://www.perueduca.pe/web/region-huanuco-grupo-2/blog/-/blogs/enfoque-por-competencias-y-rutas-de-aprendizaje

Morales, E. (julio, 2009). El uso de los videojuegos como recurso de aprendizaje en educación primaria y Teoría de la Comunicación. Dialogos de la comunicación, 78. Recuperado de http:// dialogosfelafacs.net/wp-content/ uploads/2012/01/80-revista-dialogos-videojuegos-en-educacion-primaria.pdf

Norambuena, P. \& Le-Quesne, V. (2005). La identidad cultural como fuente de aprendizaje significativo. GEOENSENANZA, 10(2), 219-234.

OSIPTEL. (2014). Encuesta Residencial de Servicios de Telecomunicaciones. Recuperado de https://www.osiptel.gob. pe/repositorioaps/data/1/1/1/par/ erestel-2014-servicios-telecomunicaciones-hogares/ERESTEL\%2020122014.pdf

OSIPTEL. (julio, 2015). Reporte estadístico. Recuperado de https://www.osiptel. gob.pe/Archivos/Publicaciones/reporte_estadistico_n12/index.html\#1/z 
Padilla-Zea, N., Medina-Medina, N., Gutiérrez-Vela, F., López-Arcos, J., Paderewsk, P. \& González-González, C. (2015). A design process for balanced educational video games with collaborative activities. Recuperado de http://www.sci.unal.edu.co/ scielo.php?script $=$ sci_arttext $\&$ pi$\mathrm{d}=$ S0012-73532015000500028\&ln$\mathrm{g}=\mathrm{pt} \& \mathrm{nrm}=\mathrm{iso}$

Padilla-Zea, N., Medina, N., Gutiérrez, F., Paderewski, P., López-Arcos, J., Núñez, M., \& Rienda, J. (2015). Evaluación continua para aprendizaje basado en competencias: Una propuesta para videojuegos educativos. IE Comunicaciones Revista Iberoamericana de Informática Educativa, 25-38.

Sarracino, F. (2014). ¿Mejora la realidad aumentada el aprendizaje de los alumnos
? Una propuesta de experiencia de museo aumentado. Profesorado: Revista de curriculum y formación del profesorado, 18(3). Recuperado de http://www.ugr. es/ recfpro/rev183ART10.pdf

Soriano, A., González, J. \& Gutiérrez, F. (2015). Realidad Aumentada en Videojuegos Educativos basados en el Contexto. FAZ, 8, 29-39.

Vargas, C. (2013). Estrategias didácticas para el desarrollo de la identidad cultural Mochica en educación primaria en una Institución Educativa de San José de Moro - La Libertad . Lima: PUCP.

Vicent, N., Rivero, P. \& Feliu, M. (2015). Arqueología y tecnologías digitales en Educación Patrimonial. Educatio Siglo XXI, 33(1), 83-102. 